\title{
Characterization techniques coupled with mathematical tools for deepening asphaltenes structure
}

\author{
Barbara Apicella ${ }^{1, *}$, Anna Ciajolo ${ }^{1}$, Andrea Carpentieri ${ }^{2}$, Ciprian Popa ${ }^{3}$ and Carmela Russo ${ }^{1}$ \\ 1 Istituto di Scienze e Tecnologie per l'Energia e la Mobilità Sostenibili, STEMS-CNR P.le Tecchio, \\ 80-80135 Naples, Italy; barbara.apicella@stems.cnr.it (B.A.); anna.ciajolo@cnr.it (A.C.); \\ carmela.russo@stems.cnr.it (C.R.) \\ 2 Dipartimento di Scienze Chimiche, Università "Federico II", Via Cintia - 80125 Napoli, Italy; \\ acarpent@unina.it (A.C.) \\ 3 Istituto Nazionale di Astrofisica - INAF, Salita Moiariello, 16 80131, Napoli, Italy; ciprian.popa@inaf.it (C.P.) \\ * Correspondence: barbara.apicella@stems.cnr.it
}

\begin{abstract}
Asphaltenes constitute a heavy fraction of fossil fuels and their characterization is still a very difficult and challenging issue due to their complex and variable composition.

Asphaltene components are highly condensed aromatic molecules having some heteroatom and aliphatic functionalities. Their molecular weights distribution span a wide range, from hundreds to millions of units, in dependence on the diagnostic used, leading to speculation about possible occurrence of self-aggregation.
\end{abstract}

In the present work, mass spectrometry, with properly developed mathematical methods, size exclusion chromatography and X-ray diffraction analysis have been applied to asphaltenes for giving some further insight on their MW distribution and characteristics.

The results here reported give further quantitative support to the experimental data interpretation already reported in previous works.

Keywords: Asphaltenes 1; mass spectrometry 2; DBE 3; Size exclusion chromatography 4; XRD 5; Aliphaticity 6.

\section{Introduction}

Asphaltenes constitute a heavy and complex fraction of fossil fuels as coal, crude oils and their heavier derivatives, which reduce the economic value and cause adverse effects to the industry using such fuels. Their hindrance on production and processing, especially in petroleum field, has required to focus fundamental and applicative research on asphaltenes characterization finalized to either separate asphaltenes from the petroleum liquids before of refining processes or their "upgrading" to a less refractory (lighter) fraction. For both cases, it is mandatory to understand the fundamental chemistry of asphaltenes [1] that is still a very difficult and challenging issue due to their complex and variable composition.

Asphaltenes are dark-brown-to-black friable solids, without a definite melting point, which foam, swell and leave a carbonaceous residue upon heating [2]. Usually, asphaltenes are operationally defined as insoluble compounds in aliphatic hydrocarbons such as n-pentane or n-heptane, and soluble in aromatics such as toluene and benzene [3]. Because of their definition as a solubility class, asphaltenes differ from a chemical class, 
and variability among asphaltenes content and composition in dependence on their source is observed [4].

Asphaltene components are highly condensed aromatic molecules having some heteroatom (oxygen-, nitrogen-sulfur- and so on) and aliphatic functionalities. An intense debate has regarded the determination of molecular weights spanning a wide range, from hundreds to millions of units in dependence on the diagnostic used [5,6], leading to speculation about self-aggregation [7], possibly favoured by the relatively high content of undesired heteroatoms and metals [8].

In the present work, mass spectrometry, with properly developed mathematical methods, size exclusion chromatography and X-ray diffraction analysis have been applied to asphaltenes for giving some further insight on their MW distribution and characteristics.

\section{Materials and Methods}

Asphaltenes studied in this work derive from a \#6 commercial heavy oil and were separated as the alkane-insoluble/aromatic soluble fraction by using the ASTM D3279 method.

\subsection{Laser desorption ionization-time of flight mass spectrometry (LDI-TOFMS)}

LDI-TOFMS spectra of asphaltenes were recorded on a SCIEX TOF/TOFTM 5800 System on positive reflectron mode, using a $\mathrm{N}_{2}$-laser. The laser power was varied from low $(40 \%$ of the nominal value) up to high values ( $90 \%$ of the nominal value). The target was prepared by depositing on a standard stainless steel plate the sample in $\mathrm{N}$-methylpyrrolidinone (NMP) and by heating in oven at about $100^{\circ} \mathrm{C}$ for few minutes for evaporating the solvent. Each spectrum represents the sum of 12,000 laser pulses from randomly chosen spots per sample position. Matrices were not added since asphaltenes, as in general carbon materials, are able to absorb the laser beam $(\lambda=337 \mathrm{~nm})$, acting as a self-matrix. [9-11].

Fast Fourier Transform (FFT) analysis was applied to asphaltenes spectra to compute the discrete Fourier transform (DFT) of repetitive signals. For data analysis, a graphic software (Origin) was used. More details on the method as applied to mass spectra are reported in [12].

The DBE number, also called degree of unsaturation, was calculated for asphaltenes from the structure of the chemicals, considering that each $\pi$ bond or ring generates one DBE. If the compound contains the elements $\mathrm{C}, \mathrm{H}, \mathrm{O}$, and $\mathrm{N}$, the DBE for the general formula $\mathrm{C}_{\mathrm{x}} \mathrm{H}_{\mathrm{y}} \mathrm{N}_{\mathrm{z}} \mathrm{O}_{\mathrm{n}}$ is calculated as follows [13]:

$\mathrm{DBE}=\mathrm{x}-\mathrm{y} / 2+\mathrm{z} / 2+1$.

In this work the DBE was determined for each mass peak considering the simplified formula for $\mathrm{C}_{\mathrm{x}} \mathrm{H}_{\mathrm{y}}$ hydrocarbons: $\mathrm{DBE}=\mathrm{x}-(\mathrm{y} / 2)+1$ by an home-made software [14]. By plotting the DBE number and the relative intensity against the carbon number $(\mathrm{CN})$, iso-abundance graphs were drawn in the Origin software.

More details are reported in [14] 


\subsection{Size exclusion chromatography (SEC)}

SEC analysis of asphaltenes was carried out on a HPLC system HP1050 series by elution with NMP on a PL-gel polystyrene-polydivinylbenzene individual-pore column (Polymer Laboratories Ltd., UK, part no. PL1110-6525 particle size of $5 \mu \mathrm{m}$ diameter and a pore dimension of $50 \mathrm{~nm}$ ) for the MW determination in the 100-50 000 Da range. The relation between retention times and molecular mass of polystyrenes has shown to be held also for PAH standards (toluene, dicoronylene, paracyclophane, pyrene and a standard PAH mixture (Supelco EPA $525 \mathrm{PAH}$ mix A)). The injection volume was $100 \mu \mathrm{L}$ and the analyses were performed at a constant temperature of $70{ }^{\circ} \mathrm{C}$ with a flow rate of $0.5 \mathrm{~mL} \mathrm{~min}{ }^{-1}$. The online detection of species eluted from the SEC column used a HP1050 UV-visible diode array detector that measured the absorbance signal at fixed absorption wavelengths $(350 \mathrm{~nm})$.

Asphaltenes samples were prepared in NMP with the concentration of $100 \mathrm{ppm}$.

\section{$2.3 \mathrm{X}$-ray diffraction $(\mathrm{XRD})$}

XRD spectra were acquired on a Bruker D2 II with Cu Catode $(\mathrm{K} \alpha 11.54 \AA$, $30 \mathrm{kV}$ voltage and $10 \mathrm{~W}$ power; $0.1^{\circ}$ slit divergence e $1.5^{\circ}$ Soller slit). A Ni filter was employed for removing $\mathrm{K} \beta(\lambda=1.392 \AA) \mathrm{X}$-ray spectral lines of copper. Instrument resolution: $0.05^{\circ} 2 \theta$. The holder is a "Zero background holder " in silicon crystal.

\section{Results}

The LDI-TOFMS mass spectrum of asphaltenes reported in Fig.1 is very complex as featured by a large number of peaks differing for only $\mathrm{m} / \mathrm{z} 1$ and distributed in a unique broad MW mode ranging from about 350 up to $850 \mathrm{u}$, with a maximum around m/z 550 . Mathematical methods applied to mass spectra featured by a high number of peaks are helpful for extrapolating quantitative compositional features of complex samples as asphaltenes.

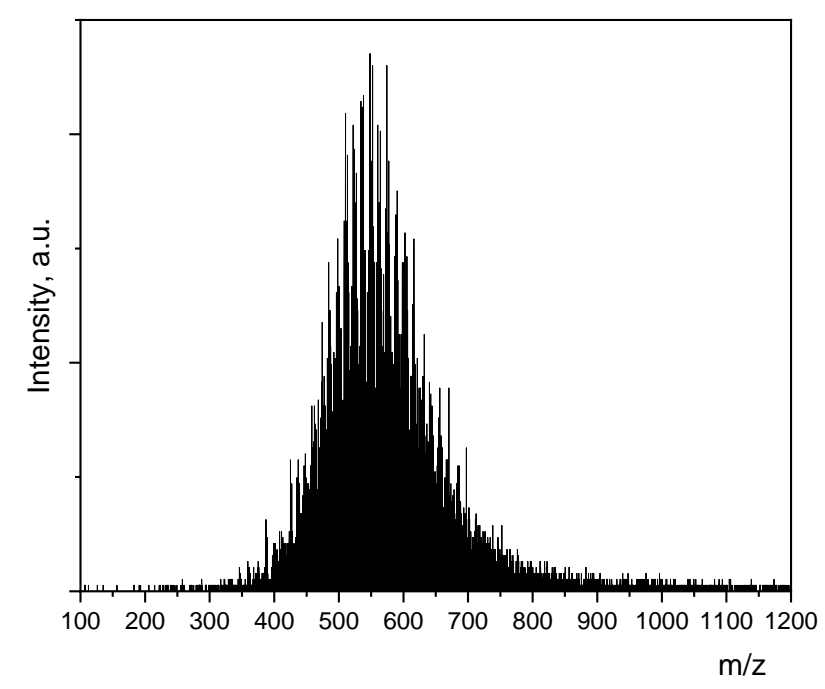

Figure 1. LDI-TOFMS spectrum of asphaltenes at low laser power (40\% of its nominal value).

Applying the FFT analysis, shown in Fig.2, the spectrum is reduced to few peaks associated to main periodicities, indicative of compositional features as below reported. 


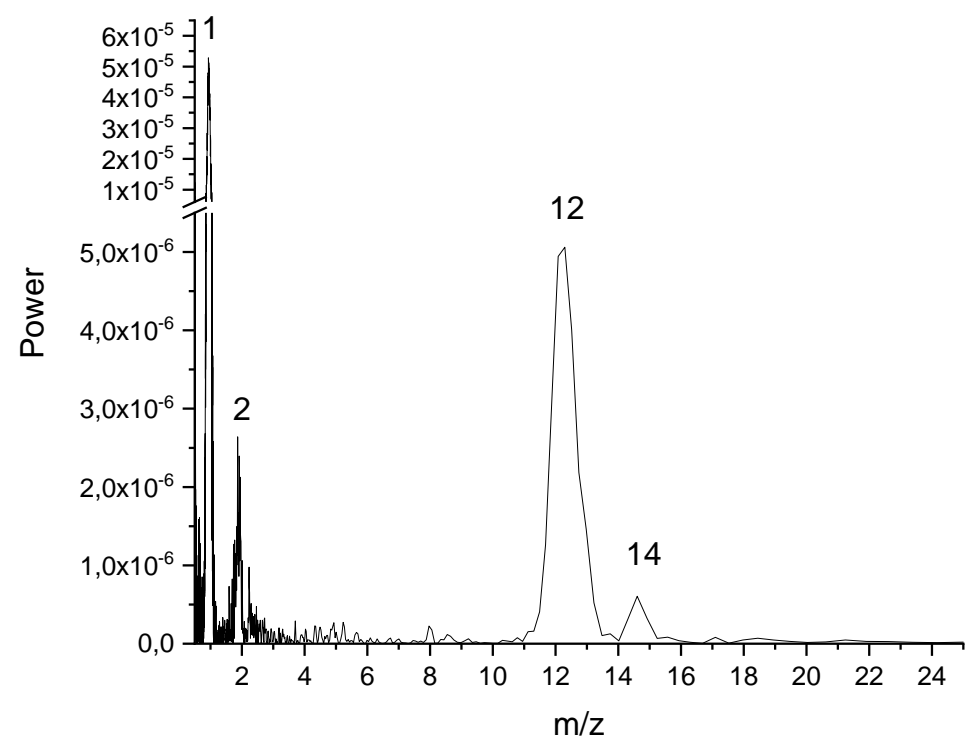

Figure 2. Mass periodicity evaluated by FFT of asphaltenes mass spectrum.

The main periodicity at m/z 12 of FFT profiles hints to homologous series of aromatic carbon polymers with a different degree of unsaturation suggested by the presence of mass difference of $\mathrm{m} / \mathrm{z} 1$ (the prevalent FFT peak) and 2. More in detail, periodicity at $\mathrm{m} / \mathrm{z} 12$ presents a large peak with a width at half height of $\mathrm{m} / \mathrm{z} 1$, which means some contribution of $\mathrm{m} / \mathrm{z} 13$ due not only to isotopic contribution, but probably also to the presence of aliphatic bridges $(\mathrm{CH})$ among the building block of the molecules. A smaller peak at $\mathrm{m} / \mathrm{z} 14$ suggests the presence of aliphatic bridges $\left(\mathrm{CH}_{2}\right)$ and aliphatic groups $\left(\mathrm{CH}_{3}\right)$ on and/or between the aromatic moieties, consistently with the quantitative analysis of the infrared spectrum performed in previous work [15]. Indeed, the infrared analysis has shown the high weight percentage of aliphatic hydrogen (higher than 6\%) and the very low contribution of aromatic hydrogen (less than wt.\% 1) mainly present in form of three- and four-adjacent hydrogens located at the edge of the polyaromatic systems. These results suggest the presence of long alkyl chains linked to scarcely pericondensed aromatic moieties [15]. That asphaltenes are mainly constituted of relatively small aromatic moieties connected and/or substituted by aliphatic groups is confirmed by the absence of large PAH with increasing number of carbon atoms testified by the absence of typical periodicities of $\mathrm{m} / \mathrm{z} 24[11,12,16]$.

The aliphatic content of asphaltenes can be deduced also by evaluating the slope of the planar limit line (PLL), which is the line generated from the iso-abundance plot by connecting the maximum DBE numbers at given carbon numbers [17] on the iso-abundance plots of DBE number vs. carbon number. The DBE plot and the PLL are reported in Fig. 3 for asphaltenes mass spectrum obtained at low laser power. 


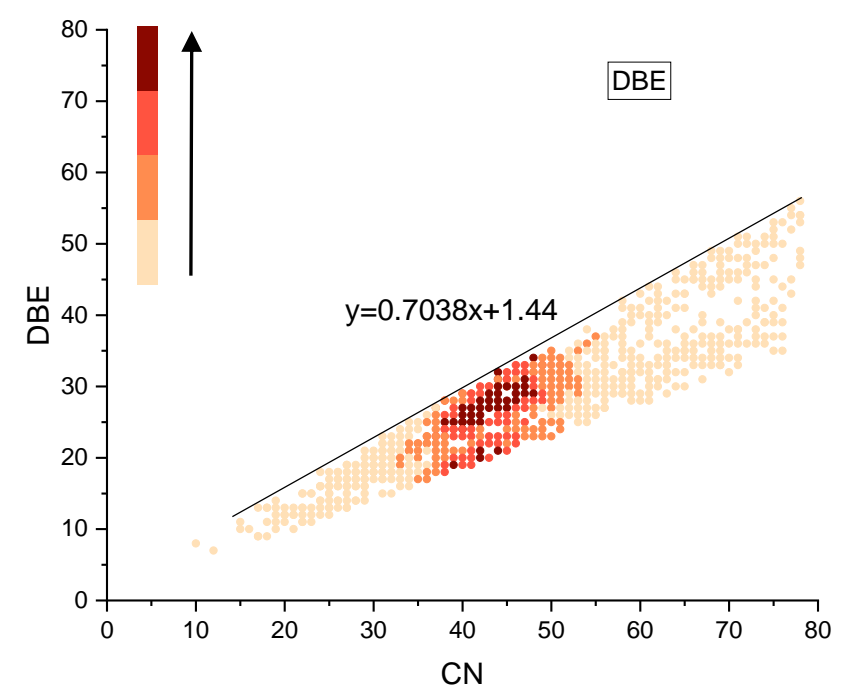

Figure 3. Iso-abundance plots of DBE number vs. carbon number of asphaltenes at low laser power ( $40 \%$ of the nominal value).

In Fig. 3 it can be seen that the PLL line has a slope of 0.704, which is lower with respect to the PLL slope typically evaluated for aromatic-rich samples like the flame-formed organic carbon (PLL slope $=0.8$ [16]) and aromatic pitch (PLL slope $=0.798,[14])$. The PLL slope of asphaltenes is even lower than that evaluated for an aliphatic pitch (PLL slope 0.717 [14]), supporting the high aliphatic content in asphaltenes observed by FFT analysis above described.

The width of the DBE distribution of asphaltenes reported in Fig. 3 shows a DBE range larger with respect to that typically evaluated for flame-formed organic carbon [16], and also for practical hydrocarbon mixtures as fossil fuels [18], and aromatic (coal) pitches [14]. The high DBE width indicates a larger variety of molecules, similarly to that observed for aliphatic (petroleum-derived) pitch [14].

The relatively low laser power value ( $40 \%$ of its nominal value) used for LDI-TOFMS measurements so far described was chosen in order to limit the fragmentation occurrence due to high laser power. Indeed, the almost complete absence of fragmentation is confirmed by the similarity of the LDI-TOFMS spectrum distribution (Fig. 1) with the mass spectrum reported in Fig.4, which has been obtained on the same asphaltenes sample with a softer ionization method, namely atmospheric pressure photoionization [19]. Nevertheless, just the high laser power has been exploited for giving insight in the aliphatic/aromatic character of asphaltenes. 


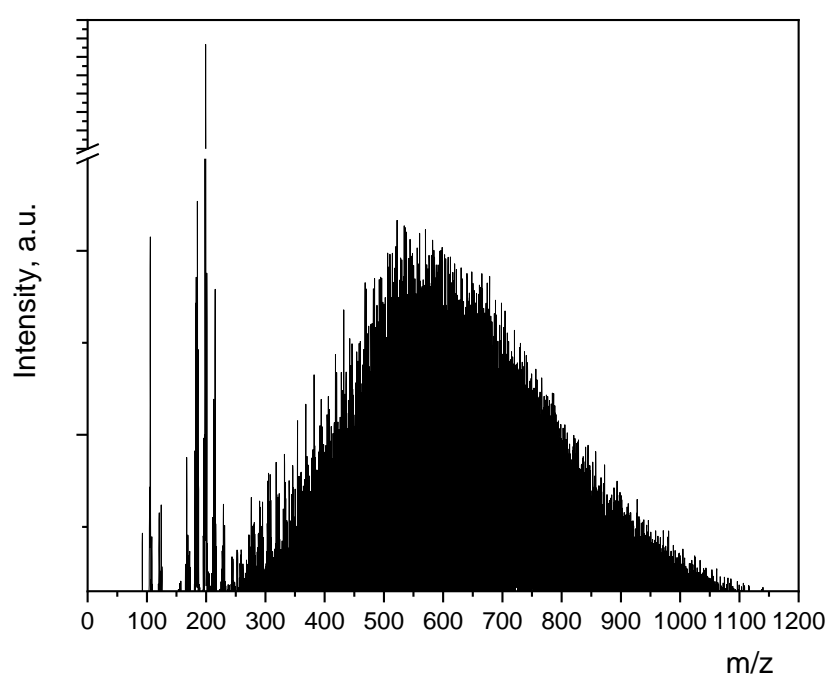

Figure 4. APPI-MS of asphaltenes (adapted from [19]).

The aliphatic/aromatic nature of asphaltenes is confirmed by measuring the mass spectrum of asphaltenes at high laser power ( $90 \%$ of its nominal value) (Fig.5).

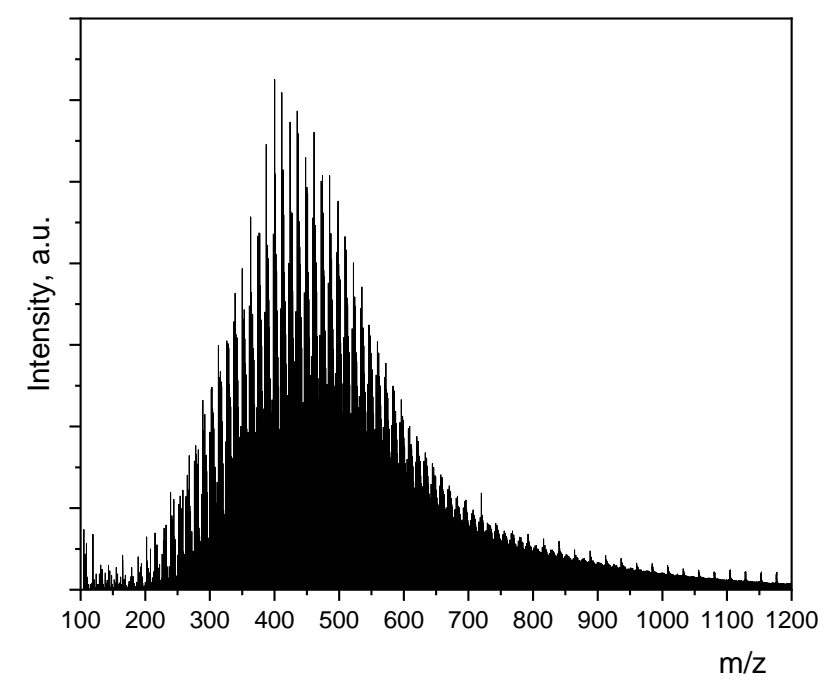

Figure 5. LDI-TOFMS of asphaltenes at high laser power ( $90 \%$ of the nominal value).

It can be noticed that increasing the laser power, the MW shift to lower masses in the range from about $\mathrm{m} / \mathrm{z} 150$ up to 1000 , with a maximum around $\mathrm{m} / \mathrm{z} 400$. The higher laser power causes the fragmentation mainly occurring in the aliphatic part of the macromolecules, as previously found for aliphatic pitch, which are alky-substituted PAH oligomers (mainly dimers) [16]. The DBE plot of the spectrum measured in the higher laser power conditions reported in Fig.6 puts better in evidence the shift to lower $\mathrm{CN}$ values of the more intense peaks (indicated with the darker colours) and the extension increase of the mass peaks range. Specifically, at lower laser power the $\mathrm{CN}$ range of the intense peaks lies between 35 and 55, whereas at high laser power lies between 20 and 50 . 


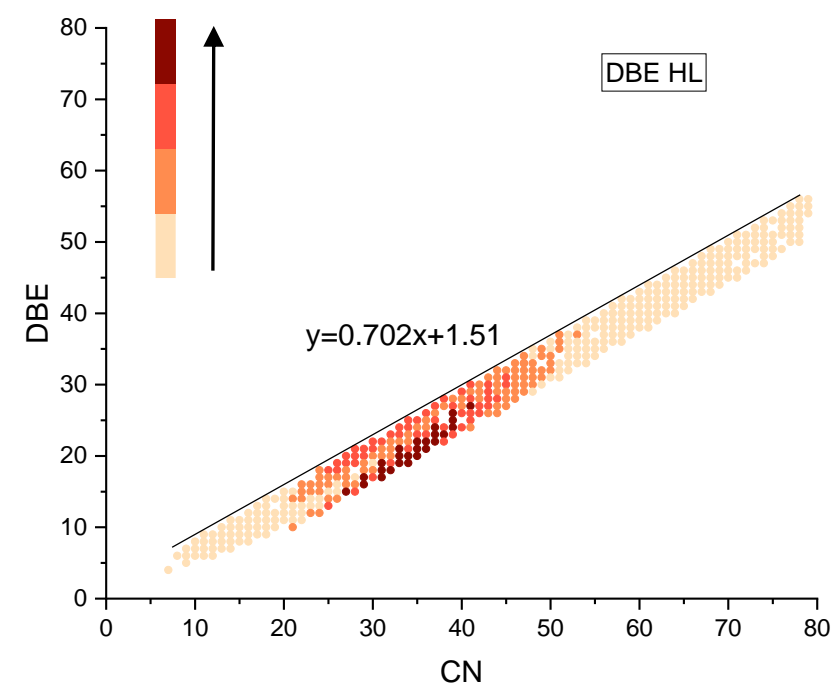

Figure 6. Iso-abundance plots of DBE number vs. carbon number of asphaltenes at high laser power. ( $90 \%$ of the nominal value).

SEC analysis is another way that has been used to evaluate the MW range of asphaltenes [20]. In comparison to the LDI-TOFMS spectrum, the SEC profile of asphaltenes, reported in Fig.7, shows a peak in a wider MW range (300-4000 u), as already found for other complex carbon materials. [21].

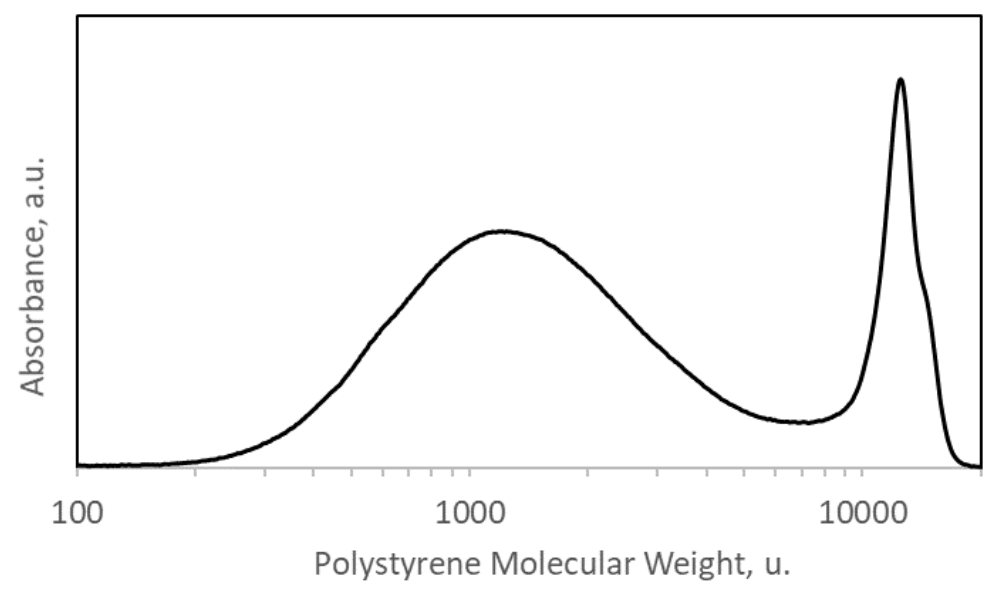

Figure 7. MW profile measured by SEC of asphaltenes at $350 \mathrm{~nm}$ absorbance wavelength for the detection.

A peak in the region around 20,000 $\mathrm{u}$ is also shown, whose nature is still unknown. In agreement with previous work [22], it can be argued that the very high MW peak could be due to asphaltenes aggregates formed as consequence of the occurrence of supramolecular aggregation, which complicates a lot the asphaltenes chemistry, making difficult to distinguish between covalent and non-covalent bonds $[5,6]$. 
The difference in the MW distribution of asphaltenes is well evidenced by comparing the number-average molecular weight $\left(\mathrm{M}_{\mathrm{n}}\right)$ evaluated on their LDI-TOFMS and SEC profiles.

The $\mathrm{Mn}_{\mathrm{n}}$ has been evaluated in the 150-4000 $\mathrm{u}$ range, assuming the intensity of the mass spectrometric and SEC signals proportional to concentration through the formula [21]:

$$
M_{n}=\frac{\sum_{i} I_{i} M W_{i}}{\sum_{i} I_{i}}
$$

where $I_{i}$ is the signal intensity and $M W_{i}$ represents the MW for each point $\mathrm{i}$ of the SEC profile and mass spectrum.

The weight-average molecular weight $\left(\mathrm{M}_{\mathrm{w}}\right)$ is calculated through the formula:

$$
M_{w}=\frac{\sum_{i} I_{i}(M W)_{i}^{2}}{\sum_{i} I_{i} M W_{i}}
$$

The $\mathrm{M}_{\mathrm{n}}$ value obtained by LDI-TOFMS for asphaltenes by LDI-TOFMS is $569 \mathrm{u}$, significantly different and lower in comparison with the $\mathrm{M}_{\mathrm{n}}$ evaluated from the SEC profiles (measured at $350 \mathrm{~nm}$ ), which is $1560 \mathrm{u}$. The smaller $\mathrm{Mn}_{\mathrm{n}}$ values measured by LDI-TOFMS can be due to the different MS detector responses to low and high-MW components. In fact, an intrinsic limitation of the LDI-TOFMS technique applied to blends of low- and high-MW species is the predominance of the signals of the high volatile low-MW species obscuring the high-MW species detection [21]. However, a correct choice of experimental conditions (especially laser power) can help to reduce this bias [23].

The $\mathrm{M}_{\mathrm{w}}$ of asphaltenes evaluated by LDI-TOFMS and SEC are 587 and $2789 \mathrm{u}$, respectively.

Thus, the polydispersity index (PDI), calculated as ratio between $\mathrm{M}_{\mathrm{w}}$ and $\mathrm{M}_{\mathrm{n}}$ is 1.03 for LDI-TOFMS and 1.79 for SEC, confirming quantitatively the observation of a much larger distribution observed by SEC.

In order to confirm the high aliphatic character of asphaltenes, $\mathrm{X}$-ray diffraction has been also applied. The XRD spectrum, reported in Fig.8, shows two main peaks attributable to the (002) reflection of graphite and the $\gamma$ band. The (002) reflection is located at $25^{\circ}$, shifted with respect to graphite value $\left(26^{\circ}\right)$, and is very weak and diffuse compared with that of graphite, as typically occurs for amorphous materials [24]. The $\gamma$ band, generally ascribed to aliphatic content $[24,25]$, is not simply a shoulder of the (002) peak as generally found in amorphous-like carbon material [25], but is a peak comparable with the (002). It clearly indicates the very high aliphatic contents of asphaltenes. The two very narrow peaks are due to the metals present in the asphaltenes sample. 


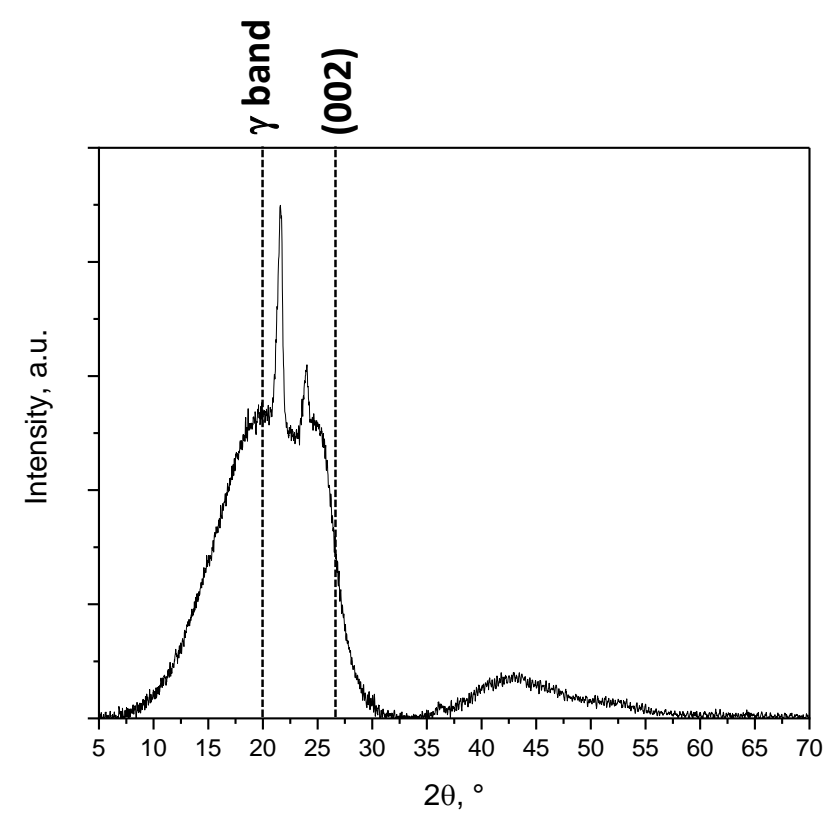

Figure 8. X-ray diffraction patterns of asphaltenes, with indication of the positions of main peaks: (002) graphite reflection and the $\gamma$ band.

\section{Final remarks}

Peculiar features of LDI-TOFM spectra of asphaltenes were observed by applying mathematical methods as FFT and DBE. These characteristics confirmed that asphaltenes are composed of relatively small aromatic moieties linked and/or substituted by aliphatic chains with MW extending up to about 1000-1500 u. SEC also showed a similar continuous distribution of species but shifted toward higher MW values. Considering the higher response of mass spectrometry to more volatile species from one side and from the other side, the possible limitations of the PS calibration reliability (successfully tested on fully aromatic standards as PAHs) for complex mixed aromatic/aliphatic compounds, the true MW probably falls between the maximum LDI-TOFMS and SEC values, in the range of $700-1000 \mathrm{u}$ assumed as the average MW of diverse samples of asphaltenes.

Author Contributions: Conceptualization, B.A.; investigation and data curation, B.A.; A.C.; C.P.; C.R. writing-original draft preparation, B.A.; writing-review and editing, B.A.; A.C.; C.R. All authors have read and agreed to the published version of the manuscript." Please turn to the CRediT taxonomy for the term explanation. Authorship must be limited to those who have contributed substantially to the work reported.

Funding: This research received no external funding.

Conflicts of Interest: The authors declare no conflict of interest

\section{References}

1. Mullins, O.C.; Sheu, E.Y.; Hammami, A.; Marshall, A.G. Asphaltenes, Heavy Oils, and Petroleomics; Springer Science and Business Media: New York, NY, USA, 2007.

2. Mullins, O.C.; Sheu, E.Y. Structures and Dynamics of Asphaltenes; Springer Science and Business Media:New York, NY, USA, 2013.

3. Speight, J.G. Petroleum Asphaltenes-Part 1: Asphaltenes, Resins and the Structure of Petroleum. Oil Gas Sci. Technol. 2004, 59, 467-477.

4. Wen, C.S.; Chilingarian, G.; Yen, T.F. Properties and structure of bitumens. In Bitumens, Asphalts and Tar Sands;Elsevier: Amsterdam, The Netherlands, 1978; Volume 7, pp. 155-190. 
5. Mullins, O.C., Martinez-Haya, B., and Marshall, A.G. Contrasting perspective on asphaltene molecular weight. This comment vs the overview of Herod, A.A., Bartle, K.D., and Kandiyoti, R. Energy Fuels, 2008, 22, 1765.

6. Herod, A.A., Bartle, K.D., and Kandiyoti, R. Comment on a paper by Mullins, Martinez-Haya and Marshall “Contrasting perspective on asphaltene molecular weight. This comment vs the overview of Herod, A.A., Bartle, K.D., and Kandiyoti, R." EnergyFuels, 2008, 22, 4312.

7. Badre, S.; Carla Goncalves, C.; Norinaga, K.; Gustavson, G.; Mullins, O.C. Molecular size and weight of asphaltenes and asphaltene solubility fractions from coals, crude oils and bitumen. Fuel 2006, 85, 1-11.

8. Vargas, F.M.; Tavakkoli, M. Asphaltene Deposition: Fundamentals, Prediction, Prevention, and Remediation; CRC Press: Boca Raton, FL, USA, 2018.

9. Przybilla L, Brand JD, Yoshimura K, Rader HJ, Müllen K. MALDI-TOF mass spectrometry of insoluble giant polycyclic aromatic hydrocarbons by a new method of sample preparation. Anal Chem 2000;72:4591.4597. https://doi.org/10.1021/ac000372q.

10. Rizzi A, Cosmina P, Flego C, Montanari L, Seraglia R, Traldi P. Laser desorption/ionization techniques in the characterization of high molecular weight oil fractions. Part 1: asphaltenes. J Mass Spectrom 2006;41(9):1232-41. https://doi.org/10.1002/jms.1095.

11. Apicella B, Carpentieri A, Alf'e M, Barbella R, Tregrossi A, Pucci P, et al. Mass spectrometric analysis of large PAH in a fuel-rich ethylene flame. Proc Comb Inst 2007;31(1):547-53. https://doi.org/10.1016/j.proci.2006.08.014.

12. Apicella, B., Bruno, A., Wang, X., Spinelli, N. Fast Fourier Transform and autocorrelation function for the analysis of complex mass spectra, Int. J. Mass Spec., 2013, 338: 30-38. doi: 10.1016/j.ijms.2013.01.003.

13. Pellegrin, V. Molecular formulas of organic compounds: the nitrogen rule and degree of unsaturation, J. Chem. Educ. 60 (8) 1983, 626-633. https://doi.org/10.1021/ed060p626.

14. Russo, C., Ciajolo, A., Stanzione, F., Tregrossi, A., Oliano, M.M., Carpentieri, A., Apicella, B. Investigation on chemical and structural properties of coal- and petroleum-derived pitches and implications on physico-chemical properties (solubility, softening and coking) Fuel, 2019, 245: 478-487. doi:10.1016/j.fuel.2019.02.040.

15. Russo, C., Stanzione, F., Tregrossi, A., Ciajolo, A., Infrared spectroscopy of some carbon-based materials relevant in combustion: Qualitative and quantitative analysis of hydrogen, Carbon 2014, 74: 127-138.

16. Apicella, B., Russo, C., Carpentieri, A., Tregrossi, A., Ciajolo, A. PAHs and fullerenes as structural and compositional motifs tracing and distinguishing organic carbon from soot. accepted for publication on Fuel, 2021, https://doi.org/10.1016/j.fuel.2021.122356.

17. Cho, Y., Kim, Y.H., Kim, S., Planar Limit-Assisted Structural Interpretation of Saturates/Aromatics/Resins/Asphaltenes Fractionated Crude Oil Compounds Observed by Fourier Transform Ion Cyclotron Resonance Mass Spectrometry, Anal. Chem. 2011, 83 (15): 6068-6073. https://doi.org/10.1021/ac2011685.

18. Niyonsaba, E., Manheim, J.M., Yerabolu, R., Kenttämaa, H.I. Recent advances in petroleum analysis by mass spectrometry. Anal Chem. 2019, 91 (1) 156-177. https://doi.org/10.1021/acs.analchem.8b05258.

19. Apicella, B. , Alfè, M., Ciajolo, A., Mass Spectrometric Advances in the Analysis of Large Aromatic Fractions of Heavy Fuel Oils and Carbon Particulates, Combust. Sci. Tech., 2010, 182: 4, 640 - 652. doi:10.1080/00102200903466335.

20. Al-Muhareb, E., Morgan, T.J., Herod, A.A., and Kandiyoti, R. Characterization of petroleum asphaltenes by size exclusion chromatography, UV-fluorescence and mass spectrometry. Pet. Sci. Technol., 2007, 25, 81.

21. Gargiulo, V., Apicella, B., Russo, C., Stanzione, F., Tregrossi, A., Millan, M., Ciajolo, A., Structural Characterization of Large Polycyclic Aromatic Hydrocarbons. Part 2: Solvent-Separated Fractions of Coal Tar Pitch and Naphthalene-Derived Pitch. Energy \& Fuels, 2016, 30(4): 2574-2583. doi:10.1021/acs.energyfuels.5b02576.

22. Strausz, O., Safarik, I., and Lown, E.M.. Cause of asphaltenes fluorescence intensity variation with molecular weight and its ramification for laser ionization mass spectrometry. Energy Fuels, 2009, 23, 1555.

23. Acevedo, S., Gutierrez, L. B., Negrin, G., Pereira J. C., Molecular Weight of Petroleum Asphaltenes: A Comparison between Mass Spectrometry and Vapor Pressure Osmometry. Energy Fuels, 2005, 19, 1548-1560.

24. Lu, L., Sahajwalla, V., Kong, C., Harris D. Quantitative X-ray diffraction analysis and its application to various coals Carbon, 2001, 39: 1821-1833.

25. Manoj, B., Kunjomana, A.G.,Study of Stacking Structure of Amorphous Carbon by X-Ray Diffraction Technique. Int. J. Electrochem. Sci., 2012, 7: $3127-3134$. 